MONNERAT, R.G.; LEAL-BERTIOLI, S.C.M.; BERTIOLI, D.J.; BUTT, T.M.; BORDAT, D. Caracterização de populações geograficamente distintas da traçadas-crucíferas por susceptibilidade ao Bacillus thuringiensis Berliner e RAPD-PCR. Horticultura Brasileira, Brasília, v.22, n.3, p.607-609, jul-set 2004.

\title{
Caracterização de populações geograficamente distintas da traça-das- crucíferas por susceptibilidade ao Bacillus thuringiensis Berliner e RAPD-PCR
}

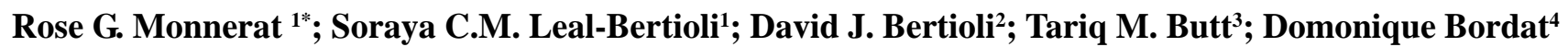 \\ ${ }^{1}$ Embrapa Recursos Genéticos e Biotecnologia, C. Postal 02372, 70770-900 Brasilia-DF; E-mail: rose@ cenargen.embrapa.br; ${ }^{2}$ Universidade \\ Católica de Brasília, Pós Graduação Campus II, SGAN 916, 70790-160 Brasília-DF; ${ }^{3}$ University of Wales Swansea, Singleton Park, Swansea, \\ SA2 8PP, Wales, UK; ${ }^{4}$ CIRAD-AMIS, Laboratoire Entotrop, BP 5035, 34032 Montpellier Cedex 1, France; *Autor correspondente
}

\section{RESUMO}

Quatro populações de Plutella xylostella (L.) (Lepidoptera: Yponomeutidae) oriundas do Brasil, Ilha da Reunião, Filipinas e Benin foram avaliadas quanto à suscetibilidade ao B. thuringiensis através de bioensaios e quanto à variabilidade genética, através de RAPD-PCR. Os dois parâmetros avaliados mostraram similaridade de resultados entre as populações, sugerindo que as mesmas devem ser bastante homogêneas, embora estejam geograficamente distantes.

Palavras-chave: Brassicaceae, Plutella xylostella, variabilidade genética, controle biológico.

\begin{abstract}
Characterization of geographically distinct populations from plutella xylostella to $B$. thuringiensis berliner and RAPD-PCR.

Four populations of Plutella xylostella (L.) (Lepidoptera: Yponomeutidae) isolated in Brazil, Reunion Island, Philippines and Benin were evaluated for susceptibility to $B$. thuringiensis. Genetic variability was accessed by RAPD analysis. Although the populations were originated from diverse geographical origins, the two evaluated parameters showed a high degree of similarity. This suggests that although the populations were geographically distant, they have a high degree of similarity.
\end{abstract}

Keywords: Brassicaceae, Plutella xylostella, genetic variability, biological control.

\section{(Recebido para publicação em 15 de junho de 2003 e aceito em 24 de maio de 2004)}

A traça-das-crucíferas, Plutella xylostella (L.) (Lepidoptera: Yponomeutidae), é considerada como uma das pragas mais importantes das plantas da família Brassicaceae no Brasil e no mundo (Talekar e Shelton, 1993). Os danos por ela causados acarretam a depreciação do produto, o atraso no crescimento da planta e mesmo a sua morte. Este inseto é originário provavelmente da região Mediterrânea e está presente nos cinco continentes. $\mathrm{O}$ custo para o seu controle pode representar até $50 \%$ do custo total da sua produção (Lim, 1986).

Dentre as diferentes técnicas de supressão populacional da traça-dascrucíferas, o controle químico tradicional é sem sombra de dúvida o mais empregado. Ainda que os danos por ela causados justifiquem a adoção dessa medida de controle, sua implementação traz riscos de intoxicação de produtores, animais domésticos e selvagens, pode deixar resíduos nos alimentos, que são consumidos via de regra in natura ou com pouco preparo. Também existe a possibilidade de contaminação do ambiente e danos aos inimigos naturais da praga. O uso contínuo e desordenado destes agentes pode ainda resultar na seleção de populações resistentes, existindo, na região do Distrito Federal, resistência de $P$. xylostella a piretróides (Castelo Branco e Guimarães, 1990).

Como alternativa ao controle químico, métodos biológicos têm sido estudados e desenvolvidos, cabendo mencionar o uso de inimigos naturais, como parasitóides, predadores e microrganismos entomopatogênicos (Monnerat e Bordat, 1998). O microrganismo mais amplamente utilizado em controle biológico é o Bacillus thuringiensis (Bt). Esta bactéria produz uma ou várias proteínas tóxicas para a traça-das-crucíferas (Monnerat et al., 1999), tendo como grande vantagem de utilização sua especificidade aos insetos sensíveis, seu efeito não poluente ao meio ambiente, sua inocuidade aos mamíferos e invertebrados e ausência de toxicidade às plantas (Whiteley e Schnepf, 1986; OMS., 1987).

Cabe salientar que existem relatos de migração da traça-das-crucíferas em várias partes do mundo, sugerindo a existência de diferentes populações, que podem ter suscetibilidades diferentes ao Bt. Trabalhos recentes têm sido realizados para verificar a variabilidade genética entre populações em diversas espécies de insetos por meio da análise molecular do DNA (Frohlich et al., 1999; Lima et al., 2002).

Este trabalho foi realizado para verificar se quatro populações de $P$. xylostella oriundas de diferentes partes do mundo apresentavam diferenças quanto a susceptibilidade ao $B$. thuringiensis e variabilidade genética, observada em reações de RAPD-PCR.

\section{MATERIAL E MÉTODOS}

Os insetos utilizados foram coletados na Ilha da Reunião, Brasil, Benin e Filipinas, e mantidos em laboratório nas seguintes condições: Temperatura: $28^{\circ} \mathrm{C} \pm 2$, fotoperíodo: $14 / 10 \mathrm{e}$ UR: $70 \%$.

Os testes de suscetibilidade foram realizados por meio de bioensaios, conduzidos com larvas de segundo estágio da primeira geração de $P$. xylostella oriundas das diferentes localidades. Folhas de couve foram mergulhadas em 
Tabela 1. Suscetibilidade à Bacillus thuringiensis de quatro populações de Plutella xylostella oriundas de diferentes regiões. Montpellier (França), 1994.

\begin{tabular}{lcc}
\hline Origem da população & CL50 (mg/ml) 2 dias & CL50 (mg/ml) 5 dias \\
\hline Ilha da Reunião & $12,41(9,47-16,27)$ a & $2,06(1,61-2,63)$ a \\
Brasil & $13,34(10,07-17,66)$ a & $2,33(1,82-2,98)$ a \\
Benin & $15,90(12,14-21,06)$ a & $3,24(2,84-3,69)$ a \\
Filipinas & $16,21(12,30-21,36)$ a & $2,52(2,19-2,90)$ a \\
\hline
\end{tabular}

Os valores obtidos em cada coluna, seguidos pela mesma letra não diferem entre si ao nível de $5 \%$ pelo teste de Newman-Keuls.

Tabela 2. Matriz do coeficiente de similaridade genética de quatro populações de $P$. xylostella, baseado na porcentagem de bandas co-migrantes em gel de eletroforese. Harpenden (UK), Rothamsted, 1994.

\begin{tabular}{l|cccc}
\hline Ilha da Reunião & 100 & & & \\
Brasil & 88.9 & 100 & & \\
Benin & 86.1 & 75.0 & 100 & 100 \\
Filipinas & 83.3 & 77.8 & 91.7 & Filipinas \\
\hline & Ilha da Reunião & Brasil & Benin & \\
\hline
\end{tabular}

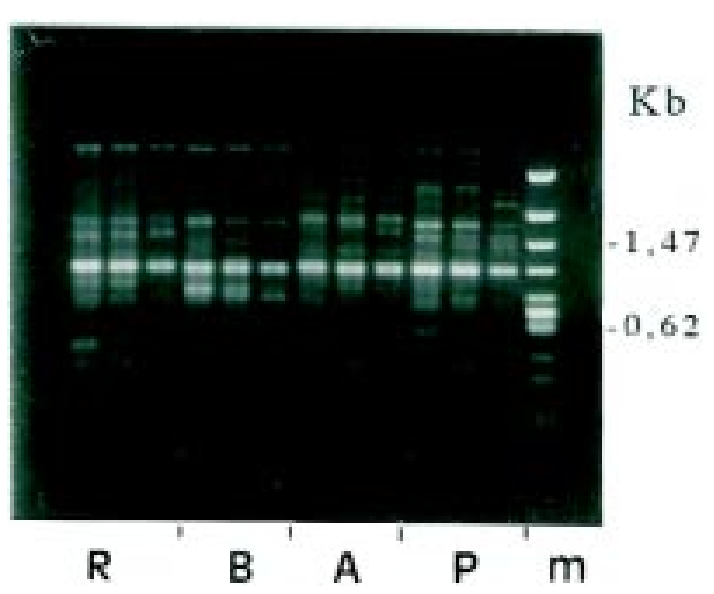

Figura 1. Perfil de RAPD-PCR das populações de Plutella xylostella oriundas da Ilha da Reunião (R 1,2,3), Brasil (B 1,2,3), Benin (A 1,2,3) e Filipinas (P 1,2,3) usando o oligonucleotídeo OPK-02; marcador de peso molecular Lambda/HindIII, pUC19/TaqI/ Sau3AI (m). Harpenden (UK), Rothamsted, 1994.

diluições decimais $\left(10^{-1}\right.$ a $\left.10^{-8}\right)$ preparadas com um formulado à base de $B$. thuringiensis var. kurstaki (Tabashnik et $a l .$, 1990). Para cada diluição foram feitas três repetições, contendo, cada uma, 50 larvas. A mortalidade larval foi avaliada dois e cinco dias após o início do ensaio e a $\mathrm{CL}_{50}$ (concentração necessária para matar $50 \%$ da população exposta) foi calculada por meio da análise de Probit (Finney, 1971).

A variabilidade genética de $P$. xylostella foi obtida pela extração e amplificação do DNA. Para a obtenção do DNA foram avaliados os protocolos de extração descritos por Black et al. et al. (1992).

O protocolo descrito por Black et al. (1992) foi selecionado e consistiu em (a) macerar os insetos em tampão TES (100 mM TRIS, pH 8,0, 10 mM EDTA, $2 \% \mathrm{SDS}$ ), (b) deixar o macerado em repouso por 5 minutos, (c) adicionar proteinase $\mathrm{K}$ e deixar a $37^{\circ} \mathrm{C}$ por 15 minutos, (d) sdicionar $100 \mathrm{ml}$ de água e deixar 15 minutos a $37^{\circ} \mathrm{C}$, (e) deixar a $94^{\circ} \mathrm{C}$ por 5 minutos, (f) centrifugar por 5 minutos a $13.000 \mathrm{rpm},(\mathrm{g})$ coletar o sobrenadante $(\mathrm{h})$ estocar a $-80^{\circ} \mathrm{C}$.

Dez indivíduos adultos de cada população foram utilizados para os testes
(1992), Langridge et al. (1991) e Möller intra-específicos. Dez grupos de dez adultos de cada população foram utilizados para os testes inter-específicos.

Um volume de $1 \mathrm{ml}$ da solução contendo o DNA do inseto foi misturado com os seguintes componentes: (1) 2,5 $\mathrm{ml}$ de tampão de reação $(100 \mathrm{mM}$ tris$\mathrm{HCl} \mathrm{pH} 8,8 ; 50 \mathrm{mM} \mathrm{KCl}, 15 \mathrm{mM} \mathrm{Mg}$ $\mathrm{Cl} 2$ e $1 \%$ de detergente não iônico), (2) $1,5 \mathrm{ml}$ do oligonucleotídeo $(50 \mathrm{ng} / \mathrm{ml})$, (3) 0,25 ml dNTPs a $20 \mathrm{mM}$, (4) $0,2 \mathrm{ml}$ de DNA Taq Polimerase (5U/ml, Northumbria Biologicals), (5) 19,55 ml de água bidestilada estéril.

Quinze oligonucleotídeos (kit Operon) foram utilizados neste estudo (OPA7, OPB16, OPE6, OPE16, OPF13, OPK1, OPK2, OPK5, OPK7, OPK9, OPK10, OPK11, OPK15, OPK17 e OPK18).

As amplificações foram realizadas em termociclador (Hybaid) programado da seguinte forma: (1) desnaturação inicial de 5 minutos a $94^{\circ} \mathrm{C}$, (2) 42 ciclos de desnaturação de 1 minuto a $92^{\circ} \mathrm{C}$, hibridação de 1 minuto a $35^{\circ} \mathrm{C}$ e alongamento de 1 minuto a $72^{\circ} \mathrm{C}$, (3) alongamento final de 1 minuto a $72^{\circ} \mathrm{C}$.

Os produtos foram analisados em gel de agarose $0,8 \%$ em tampão TBE (45mM TRIS, $45 \mathrm{mM}$ de ácido bórico, $1 \mathrm{mM}$ EDTA pH 8,0) e as bandas visualizadas em luz ultra-violeta.

Para a análise das bandas, os perfis eletroforéticos foram analisados através do programa estatístico Genstat (Payne et al., 1987) e a matriz de similaridade genética foi calculada através do coeficiente de similaridade de Jaccard (Sneath e Sokal, 1973).

\section{RESULTADOS E DISCUSSÃO}

B. thuringiensis var. kurstaki apresentou o mesmo nível de toxicidade contra as quatro populações de $P$. xylostella. Os valores de $\mathrm{CL}_{50}$ encontrados após dois e cinco dias (Tabela 1) foram estatisticamente similares, variando de 12,41 a $16,21 \mathrm{mg} / \mathrm{ml}$ no segundo dia e de 2,06 a 3,24 mg/ml no quinto dia, indicando que não há diferenças de suscetibilidade entre as populações. Esses resultados mostram que as toxinas produzidas pela bactéria continuam agindo mesmo após o segundo dia de aplicação, pois a $\mathrm{CL}_{50}$ encontrada na 
avaliação realizada no quinto dia foi em média 5,5 vezes inferior a $\mathrm{CL}_{50}$ obtida no segundo dia.

Três métodos de extração de DNA foram avaliados, pois não havia nenhum método descrito especificamente para a traça-das-crucíferas. Dentre esses, o método de Black et al. (1992), descrito para extração de DNA de afídeos, foi selecionado para a realização do trabalho, pois foi o único que proporcionou uma boa extração de DNA. Os outros métodos, descritos para a extração de DNA de plantas (Langridge et al., 1991) e de fungos filamentosos (Möller et al., 1992), não foram apropriados por não resultarem em um DNA de boa qualidade.

Nenhuma variabilidade genética intra-populacional foi detectada usando os 15 oligonucleotídeos mencionados ( $100 \%$ de similaridade), sugerindo que cada uma das populações são geneticamente homogêneas (Figura 1).

As amplificações RAPD-PCR com o DNA das diferentes populações geraram 37 produtos. De forma geral, as populações eram bastante homogêneas, pois o menor coeficiente de similaridade era de $75 \%$ (Tabela 2). As populações provenientes do Benin e das Filipinas eram as mais semelhantes $(91 \%)$. A população do Brasil estava mais próxima da população originária da Ilha da Reunião $(88,9 \%)$ do que as provenientes do Benin e das Filipinas, que apresentaram coeficientes de similaridade respectivamente de 75 e 77,8\% (Tabela 2).

Os dois parâmetros utilizados neste trabalho mostraram semelhanças entre as diferentes populações de P. xylostella, tan- to de suscetibilidade ao $B$. thuringiensis quanto na variabilidade genética por RAPD-PCR. A alta homogeneidade encontrada nas populações estudadas sugere uma recente irradiação desta espécie, acompanhando os movimentos do homem e da cultura das crucíferas. Estudos envolvendo maior número de populações e o emprego de outras técnicas molecular seria de grande importância para corroborar estes dados.

\section{LITERATURA CITADA}

BLACK IV, W.C.; DU TEAU, N.M.; PUTERKA, G.J.; NECHOLS J.R.; PETTORINI J.M. Use of random amplified polymorphid DNA polymerase chain reaction (RAPD-PCR) to detect DNA polymorphisms in aphids (Homoptera: Aphididae). Bulletin of Entomological Research, v.82, p.151-159, 1992.

CASTELO BRANCO, M.; GUIMARÃES, A.L. Controle da traça-das-crucíferas em repolho, 1989 Horticultura Brasileira, Brasília, v.8, n.1, p.2425, 1990.

FROHLICH, D.R.; TORREZ-JEREZ, I.; BEDFORD, I.D.; MARKHAM, P.G; BROWN, J.K A phylogeographical analysis of the Bemisia tabaci species complex based on mitochondrial DNA markers. Molecular Ecology, v.8, p.1683-1691, 1999. FINNEY D. Probit analysis. Cambridge University Press, Cambridge, p.50-80. 1971.

LANGRIDGE, U.; SCHWALL, A.; LANGRIDGE, P. Squashes of plant tissue as substrate for PCR. Nucleic Acids Research, v.19, p.69-54, 1991.

LIM, G.S. Biological control of Diamondback moth. In: TALEKAR N.S., Management of Diamondback moth and other crucifers pests: Proceedings of the first International Workshop, 11-15 mars, 1985, p.159-171. Tainan, Taiwan. Asian Vegetable Research and Development Center. 1986.

LIMA, L.H.; CAMPOS, L.; MORETZSOHN, M.; NÁVIA, D.; OLIVEIRA, M.R.V. Genetic diversity of Bemisia tabaci (Genn.) populations in Brazil revealed by RAPD markers. Genetics and Molecular Biology, v.25, n.2, p.217-223, 2002.
MÖLLER, E.M.; BAHNWEG, G.; SANDERMANN, H.; GEIGER, H.H. A simple and efficient protocol for isolation of high molecular weight DNA from filamentous fungi, fruit bodies, and infected plant tissues. Nucleic Acids Research, v.20, p.6115-6116, 1992.

MONNERAT, R.G.; MASSON, L.; BROUSSEAU, R.; PUSZTAI-CAREY, M.; BORDAT, D.; FRUTOS, R. Differential activity and activation of Bacillus thuringiensis insecticidal proteins in Diamondback moth, Plutella xylostella. Current Microbiology, v.39, p.159-162, 1999.

MONNERAT, R.G.; BORDAT, D. Influence of HD-1 Bacillus thuringiensis spp. kurstaki on the developmental stages of Diadegma sp.(Hym.: Ichneumonidae) parasitoid of diamondback moth (Lep.: Yponomeutidae). Journal of Applied Entomology, v.122, p.49-51, 1998.

ORGANISATION MONDIAL DE LA SANTE (OMS). Report of an Informal Consultation on the Detection, Isolation, Identification and Ecology of Biocontrol Agents of Disease Vectors. UNDP/ WORLD BANK/WHO Special Programme for Research and Training in tropical Deseases, TDR/ BCV/IC-GE/87.3, 41 p. 1987.

PAYNE R.W.; LANE P.W.; AINSLEY, A.E.; BICKNELL, K.E.; HARDING, P.G.N.; LEECH, P.K.; SIMPSON, H.R.; TODD, A.D.; VERRIER, P.J.; WHITE, R.J.; GOWER, J.C.; WILSON, G.T.; PATTERSON, G. Genstat 5 Reference Manual. Clarendon Press, Oxford, 134 p. 1987.

SNEATH, P.H.A.; SOKAL, R.R. Numerical Taxonomy. Freeman, San Francisco, 573 p. 1973. TABASHNIK, B.E.; CUSHING, N.L.; FINSON, N.; JOHSON, M.W. Field Development of resistance to Bacillus thuringiensis in Diamondback moth (Lep.: Plutellidae). Journal of Economic Entomology, v.83, p.1671-1676, 1990.

TALEKAR N.S.; SHELTON A.M. Biology, ecology and management of the diamondback moth. Annual Review of Entomology, v.38, p.275301, 1993.

WHITELEY, H.R.; SCHNEPF, H.E. The molecular biology of parasporal crystal body formation in Bacillus thuringiensis. Annual review of microbiology, v.40, p.549-576, 1986. 